\section{Method for Transferring Mutations between Plasmids}

\section{BioTechniques 32:44-46 (January 2002)}

The identification and isolation of protein fragments that are responsible for specialized functions such as DNA binding, transactivation, and enzymatic activity $(3,4,6)$ is a common technique for dissecting protein structure-function relationships. Subsequent functional analysis of protein fragments by mutational studies frequently aids the investigator in determining critical regions and residues of the fragment that support the specific function $(1,2)$. However, the ultimate test of biological significance requires that the functional consequences of mutations be assessed in the context of the full-length native protein inside a living cell. Therefore, transferring mutations from the initial vector expressing the protein fragment to other vectors expressing either the full-length or alternative fragments of the protein is often necessary. Common procedures for such transfer include subcloning (5), recom bination (7), and oligonucleotide-mediated site-directed mutagenesis of the target expression vector (8). However, each method has limitations: subcloning requires convenient restriction sites, recombination is limited by specific vector requirements for selection, and sitedirected mutagenesis requires a unique oligonucleotide primer pair for each mutation to be transferred. Especially when the mutations are naturally occurring or generated by random procedures, the synthesis of numerous pairs of site-directed mutagenic oligonucleotides for transfer would be costly.

As an alternative to the traditional approaches for mutation transfer, we developed a simple method for transfer that utilizes a single set of oligonucleotide primers. This technique involves (i) generating a 300-400 bp PCR product from the originally mutated template plasmid (the mutation donor) using a set of nonmutagenic primers that flank the region of interest and (ii) using this initial large PCR product as the mutagenic primer set for amplification of the mutation recipient plasmid that contains the same sequence of DNA without the mutations. In essence, the second round of PCR is similar to typical site-directed mutagenesis, except it uses a much longer primer pair rather than the standard synthetic oligonucleotides. The major advantage of this technique is that a series of mutations in a protein region can each be transferred using a single flanking primer set rather than developing and purchasing individual mutagenic primers sets for each mutation to be moved. This is both more economical and a considerable time saver when several random or naturally existing mutations in a defined region of DNA are to be mobilized. We developed this method as a quick and easy way to transfer randomly generated mutations from the bovine papillomavirus E1 DNA binding domain (E1DBD) region expressed in a yeast plasmid into the full-length E1 gene in a mammalian expression vector. Using this method, we made 25 mutation transfers and isolated 21 mutants on the first round of DNA sequencing. This result represents a high first-pass mutagenesis efficiency of $84 \%$. While our studies were confined to a single donor/recipient plasmid set, this method should function with any two appropriate plasmids and, thus, has general applicability to any situation where mutations need to be transferred from one vector to another.

The exact protocol we use is as follows, and a diagram is shown in Figure 1. The initial PCR contains $25 \mathrm{ng}$ mutation-containing template plasmid, $3 \mu \mathrm{L}$ each flanking primer ( $5 \mu \mathrm{M}$ stocks $), 0.5$ $\mu \mathrm{L} 10 \mathrm{mM}$ dNTPs, $2.5 \mu \mathrm{L} \mathrm{10 \times Pfu}$ buffer, and $0.5 \mu \mathrm{L} P f u$ DNA polymerase $(3 \mathrm{U} / \mu \mathrm{L})$ (Promega, Madison, WI, USA) in a $25-\mu \mathrm{L}$ reaction volume. PCR cycling conditions include initial denaturation at $94^{\circ} \mathrm{C}$ for $1 \mathrm{~min}$, followed by 35 cycles of $94^{\circ} \mathrm{C}$ for $3 \mathrm{~s}$, $48^{\circ} \mathrm{C}$ for $30 \mathrm{~s}, 72^{\circ} \mathrm{C}$ for $2 \mathrm{~min}$, and a final dwell at $4^{\circ} \mathrm{C}$. The initial PCR product is isolated by electrophoresis on a $1 \%$ TBE agarose gel and extraction with a QIAex ${ }^{\circledR}$ II Gel Extraction Kit (Qiagen, Valencia, CA, USA) according to manufacturer's protocol. The second PCR contains $25 \mathrm{ng}$ wild-type plasmid to be mutated, $250 \mathrm{ng}$ purified PCR product from first reaction in a volume of $10 \mu \mathrm{L}, 0.5 \mu \mathrm{L} 10 \mathrm{mM}$ dNTPs, $2.5 \mu \mathrm{L} 10 \times$ Pfu buffer, and 0.5 $\mu \mathrm{L} P f u$ DNA polymerase $(1.5 \mathrm{U})$ in a $25-\mu \mathrm{L}$ reaction volume. PCR cycling conditions include initial denaturation at $94^{\circ} \mathrm{C}$ for $1 \mathrm{~min}$, followed by $17 \mathrm{cy}$ cles of $95^{\circ} \mathrm{C}$ for $30 \mathrm{~s}, 50^{\circ} \mathrm{C}$ for $30 \mathrm{~s}$, and $72^{\circ} \mathrm{C}$ for $2 \mathrm{X}$ min where $\mathrm{X}$ is the length of plasmid in $\mathrm{kb}$, and a final dwell at $4^{\circ} \mathrm{C}$. Five units of DpnI are added directly to the finished reaction, which is then incubated at $37^{\circ} \mathrm{C}$ for $1 \mathrm{~h}$. DpnI di-

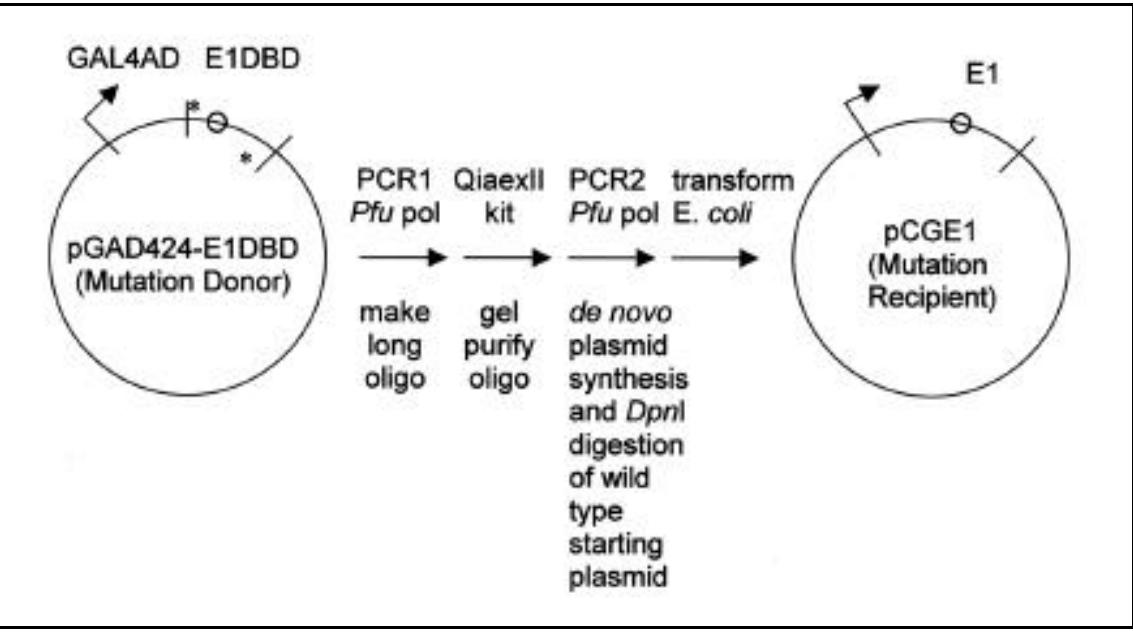

Figure 1. Diagram of mutation transfer. First, PCR with a proofreading polymerase $(P f u)$ is performed using primers (asterisks) flanking a mutation $(\mathrm{O})$ of interest. Flanking primers should be directed against parts of the gene that are also present in recipient plasmid. Second, PCR product is purified from an agarose gel. Third, long extension PCR with a proofreading polymerase is performed on a plasmid construct containing the gene to be mutated. This accomplishes de novo synthesis of a plasmid that will now contain the mutation in the context of either a new fragment of the gene or the full-length gene. Resulting PCR products are transformed into E. coli strain XL-1 Blue, which seals any nicks and amplifies the plasmid. 
gests the bacterially methylated tem plate plasmid DNA at $5^{\prime}$-GATC-3' sequences and leaves newly synthesized, unmethylated DNA intact. Two microliters of the reaction are electroporated into XL-1 Blue E. coli (Stratagene, La Jolla, CA, USA), and transformants are selected on LB agar plates containing the appropriate antibiotic. Plasmids from the colonies are then sequenced using standard techniques.

This method is highly versatile and not only allows transfer of single-point mutations but also multiple mutations simultaneously if the original mutation donor plasmid has more than one sequence change from the recipient. In addition, we have also used two sitespecific mutation-containing primers to incorporate two mutations simultaneously into the ends of the first-round PCR product. Both mutations can then be transferred to the recipient plasmid in the second round of PCR. Again, this allows incorporation of two (or possibly more) mutations into the final vector simultaneously rather than sequentially. This is especially useful if the distance between the two desired mutations is greater than can be handled effectively with synthetic oligonucleotides. In addition to point mutation transfer, it seems feasible that this method might also prove useful in generating chimeric DNAs for domain swapping or even whole gene swapping, as long as the two DNA regions to be swapped are of a similar enough sequence and size. For example, it may be possible to swap the small (approximately $400 \mathrm{bp)} \mathrm{E6} \mathrm{and}$ E7 viral oncogenes between two strains of papillomavirus since this virus contains double-stranded, circular DNA approximately $8 \mathrm{~kb}$ in length.

One limitation of this technique that we have seen is the length of the initial PCR product. For example, a product of 300 bp worked well, while 600 -bp products worked poorly, if at all. However, this is only a minor limitation for a mutation transfer procedure since 100 amino acids is a fairly large region for mutational investigation. Furthermore, if the mutations are more widely dispersed, several additional primer sets can be designed to more fully encompass the overall regions to be transferred. Overall, we believe this procedure is a useful adjunct to other mutation transfer procedures and will often prove simpler and less expensive than subcloning or traditional site-specific mutagenesis.

\section{REFERENCES}

1.Chen, G. and A. Stenlund. 2000. Two patches of amino acids on the E2 DNA binding domain define the surface for interaction with E1. J. Virol. 74:1506-1512.

2.Gonzalez, A., C. Bazaldua-Hernandez, M. West, K. Woytek, and V.G. Wilson. 2000. Identification of a short, hydrophilic amino acid sequence critical for origin recognition by the bovine papillomavirus E1 protein. J. Virol. 74:245-253.

3.Leng, X., J.H. Ludes-Meyers, and V.G. Wilson. 1997. Isolation of an amino-terminal region of bovine papillomavirus type $1 \mathrm{E} 1$ protein that retains origin binding and E2 interaction capacity. J. Virol. 71:848-852.

4.Sarafi, T.R. and A.A. McBride. 1995. Domains of the BPV-1 E1 replication protein required for origin-specific DNA binding and interaction with the E2 transactivator. Virology 211:385-396.

5.Spear, M. 2000. Efficient DNA subcloning through selective restriction endonuclease digestion. BioTechniques 28:660-668.

6.Thorner, L.K., D.A. Lim, and M.R. Botchan. 1993. DNA-binding domain of bovine papillomavirus type 1 E1 helicase: structural and functional aspects. J. Virol. 67:6000-6014.

7.Tripodi, M., S. Perfumo, R. Ali, L. Amicone, C. Abbott, and R. Cortese. 1990. Generation of small mutation in large genomic fragments by homologous recombination: description of the technique and examples of its use. Nucleic Acids Res. 18:6247-6251.

8. Watkins, B.A, A.E. Davis, F. Cocchi, and M.S. Reitz, Jr. 1993. A rapid method for sitespecific mutagenesis using larger plasmids as templates. BioTechniques 15:700-704.

We wish to thank Julian Leibowitz and Rajesh Miranda for helpful discussions during the development of this work. This work was funded through American Cander Society grant no. VM 183. Address correspondence to Dr. Van G. Wilson, Department of Medical Microbiology and Immunology, Texas A\&M University System Health Science Center, College Station, TX 778431114,USA.e-mail:v-wilson@tamu.edu

Received 17 July 2001; accepted 27 September 2001.

Michael West and
Van G. Wilson
Texas A\&M University System
Health Science Center
College Station, TX, USA

\section{Direct Fluorescent Primers Are Superior to M13-Tailed Primers for Pinus taeda Microsatellites}

\author{
BioTechniques 32:46-52 (January 2002)
}

Microsatellite marker data can be automated for high-throughput mapping projects, and automated collection methods are superior to PAGE with silver staining or radiolabeling in time, resolution, and safety. Many microsatellites can be loaded in a single lane using multiple dyes with different wavelength emissions and product size classes. The sensitivity of the automated system to fluorescently labeled PCR products reduces the amount of the required product. Automated systems have high resolution, detecting a single base-pair difference. Fluorescent dyes used in automated systems are safer and more stable than silver-staining protocols or radioisotopes.

Pine microsatellites can be especially difficult for developing high-throughput protocols because Pinus spp. genomes range from 18600 to 30000 $\mathrm{Mb}$ per haploid genome (8) and, similar to many large plant genomes, are composed mostly of highly repetitive DNA $(76 \%-86 \%)(5,10)$. Gene families are also highly duplicated (9), and duplication includes families of clustered microsatellites (7). Family members have conserved primer-binding sites and even conserved flanking regions, but repeat composition is highly variable within a family. Mispriming or suboptimal PCR amplification can result in no amplification, random priming, or am plification of non-orthologous members of the same microsatellite family. The sources of PCR-banding artifacts are highly duplicated gene families, highcopy microsatellite families, and highly repetitive DNA.

We compared the M13-tailed primer method and the direct fluorescent primer method for high-throughput microsatellite data collection using the $\mathrm{IR}^{2}$ Gene Read IR ${ }^{\mathrm{TM}} 4200$ DNA Analyzer (LI-COR, Lincoln, NE, USA). The M13-tailed primer method is based on a 